\title{
Thin layer chromatographic investigation of some veterinary drugs
}

\author{
Z.S. Hamad and B.M. Yahya \\ Department of Pharmacology, College of Pharmacy, University of Mosul, Mosul, Iraq
}

\begin{abstract}
A simple technique, using solvent extraction and thin layer chromatography for the detection and separation of a number of commonly prescribed veterinary drugs was studied. Blood and urine have been considered as possible biological samples taken from the animals. The extraction of each sample was done according to the type of the drug as it is acidic or basic, then the extract was spotted on TLC plate by capillary tube after lining the starting line first. Separations of the components of the samples were developed after running the plate in a tight lid tank containing solvent (mobile phase). The identification of separated spots were carried out after lining the end line for the solvent front then by spraying the plate with mercurous nitrate reagent for acidic drugs and acidic iodoplatinate or potassium permanganate reagent for basic drugs. The rate of flow value $\left(\mathrm{R}_{\mathrm{f}}\right)$ for each compound was measured and the color of spots were determined. This work provides a simple and rapid qualitative technique for the detection of veterinary drugs used at therapeutic doses and in overdosage.
\end{abstract}

Keywords: Thin layer chromatography; Veterinary drugs; Drug analysis.

Available online at http://www.vetmedmosul.org/ijvs

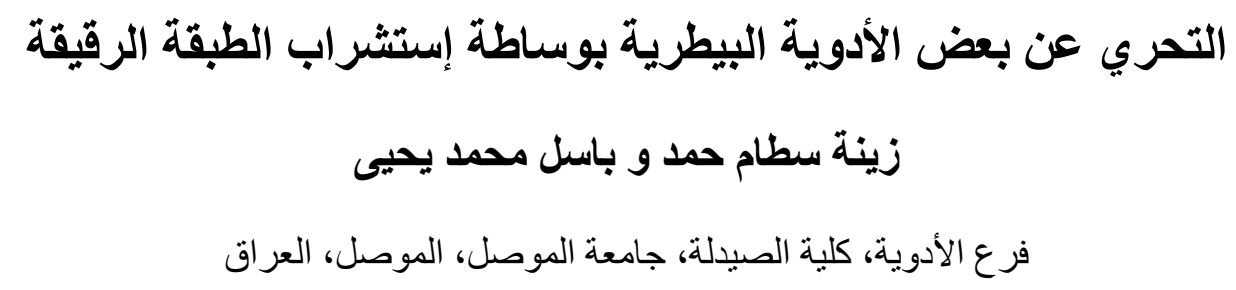

الخلاصة

وصفت هذه الدراسة طريقة بسيطة بعد عملية الإستخلاص إستعمال طريقة إستشر اب الطبقة الرقبقة لكثف وفصل عدد من الادوية

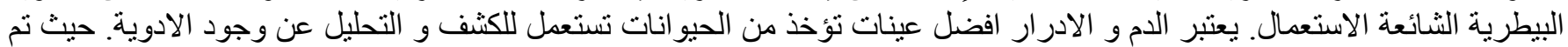

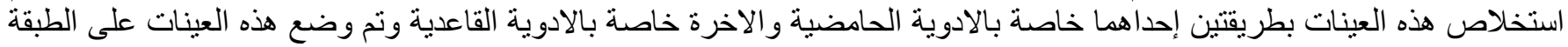

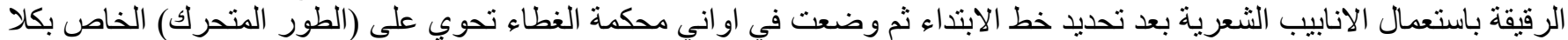

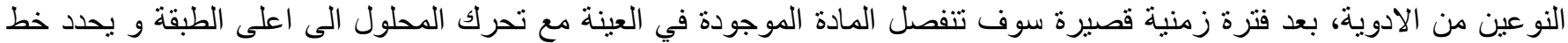

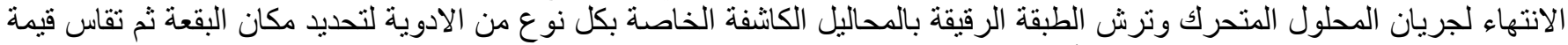

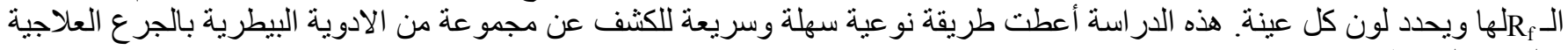
و الجرع المفرطة.

\section{Introduction}

Animal toxicoses are a frequent presenting complaint in veterinary emergency clinics and general practice (1). Over the years, biological fluid samples have been used for drug analyses (2). Identification of the drug is a prerequisite for optimal treatment (3).

The use of thin layer chromatography (TLC) for the separation and identification of compounds is one of the earliest chromatographic techniques (4). It has been increased over the past few years for drug analyses, owing to the short development time of modern plates (5). Less than one hour is usually enough to separate and identify very small amounts of a specific drug. A second advantage is the high reproducibility obtained with this technique using reproducibly coated and conditioned plates with accurate sample application technique $(6,7)$.

This work was carried out to investigate the possibility of detection and separation of a number of a commonly 
prescribed veterinary drugs which may also be used in overdose.

\section{Materials and methods}

Adult albino rats were used in this work that have been taken from animal house of the College of Veterinary Medicine, University of Mosul.

Three rats were used for each drug in this study, one $\mathrm{ml}$ of blood and urine was collected from each animal after administration of three doses of each drug, the doses represent the therapeutic dose (12) and duplicate (over dosage) given to the animals as in the following schedule.

Then blood or urine sample was divided into two parts, one part was extracted for acidic drugs and the other part for basic drugs.

\begin{tabular}{|c|c|c|c|c|}
\hline Drug & Doses $\mathrm{mg} / \mathrm{kg}$ & Route of administration & \multicolumn{2}{|c|}{ Time of sampling blood urine } \\
\hline Diphenhydramine & $5,15,30$ & i.m. & after $30 \mathrm{~min}$ & after $24 \mathrm{~h}$ \\
\hline Diazepam & $5,10,20$ & i.m. & $"$ & " \\
\hline Dexamethasone & $1,2,4$ & i.m.. & $"$ & $"$ \\
\hline Metoclopramide & $25,50,100$ & i.m. & $"$ & $"$ \\
\hline Codeine & $10,20,40$ & s.c. & $"$ & $"$ \\
\hline Atropine & $2,4,8$ & i.m. & $"$ & $"$ \\
\hline Promethazine & $5,10,20$ & i.m. & $"$ & $"$ \\
\hline Albendazole & $15,30,60$ & orally & $2 \mathrm{~h}$ & $"$ \\
\hline Chlorpheniramine & $10,20,40$ & i.m. & $30 \mathrm{~min}$ & $"$ \\
\hline Diclofenac sodium & $1,2,4$ & i.m & $"$ & $"$ \\
\hline
\end{tabular}

\section{For acidic drugs}

Hydrochloric acid $(0.25 \mathrm{ml}, 2 \mathrm{~N})$ was added to $1 \mathrm{ml}$ blood or urine in a conical glass tube followed by $5 \mathrm{ml}$ of ether. The contents of the tube were then vortexed mixed for 30 seconds. The organic layer $(4 \mathrm{ml})$ was transferred to a clean conical tube and evaporated to dryness under a stream of air in a water bath. The residue was redissolved in $50 \mu \mathrm{l}$ ether and $40 \mu \mathrm{l}$ was spotted onto the thin layer chromatographic plate using a capillary tube under a hot air stream.

The plates were thin layer plastic sheets of the nonfluorescent type (silicagele-60, $10 \times 20 \mathrm{~cm}$, Merk, Daratadt/ Germany). The plates were developed in glass tanks at $20-25^{\circ} \mathrm{C}$ with acetone: chloroform (1:9). This mixture should be prepared fresh on alternate days and the tank should be equilibrated for at least $45 \mathrm{~min}$. The plates were developed to a height of $10 \mathrm{~cm}$ and air dried for a few minutes prior spraying by mercurous nitrate reagent for location of the spots.

\section{For basic drugs}

Ammonium hydroxide $(0.25 \mathrm{ml}, 2 \mathrm{~N})$ was added to $1 \mathrm{ml}$ blood or urine in a conical glass tube followed by $5 \mathrm{ml}$ of chloroform. The contents of the tube were then vortexed for 30 seconds. $4 \mathrm{ml}$ of chloroform was taken into a clean tube and evaporated to dryness under a stream of air, and the residue was redissolved in $50 \mu \mathrm{l}$ chloroform and $40 \mu \mathrm{l}$ was spotted onto the thin layer plate.
The plates were developed with strong ammonia solution: methanol (1.5:100). After the plates were dried, they sprayed either by acidic iodoplatinate or potassium permanganate. Authentic drug samples were spotted on to the thin layer plate and were run with each series of unknown sample (5).

\section{Rate of flow values $\left(R_{f}\right)$}

The basic measurement in TLC is the $\mathrm{R}_{\mathrm{f}}$ value (5). The $R_{f}$ value is constant for a substance in a particular chromatography solvent system used. $\mathrm{R}_{\mathrm{f}}$ is a measure of the distance traveled by the compound from the origin (starting line) divided by the distance traveled by the solvent from the origin on the TLC plate. The range of $R_{f}$ value obtained is from 0 to 1 .

Generally, mobile phases have been developed which ensure that a particular drug will have a quite different $R_{f}$ value in one system compared with other. By other means, for extra confirmation of identity of a compound, more than one solvent system may be used and also different types of spray reagents may also be used for localization of the spots $(4,5)$.

\section{Results}

No endogenous substances from blood or urine were found to interfere with the method described above. 
Table (1) shows the rate of flow ( $\mathrm{R}_{\mathrm{F}}$ value) and the colour of the spot. These parameters $\left(\mathrm{R}_{\mathrm{F}}\right.$ value and colour of the spot) are important in diagnosing the unknown spots which may be revealed from any biological fluid sample $(4,5)$.

\begin{tabular}{lcccc}
\hline \multirow{2}{*}{ Drug } & \multicolumn{3}{c}{$\mathrm{R}_{\mathrm{f}}$ value } & \multirow{2}{*}{ Colour of spot } \\
\cline { 2 - 4 } & Authentic standard & Blood extract & Urine extract & Brownish \\
Diphenhydramine & 0.54 & 0.54 & 0.55 & Intense brown \\
Diazepam & 0.73 & 0.73 & $0.73^{*}$ & Bright yellow \\
Dexamethasone & 0.9 & 0.91 & 0.91 & Yellowish brown \\
Metoclopramide & 0.4 & 0.4 & $0.39^{*}$ & Intense blue \\
Codeine & 0.34 & $0.33^{*}$ & 0.34 & faint brown \\
Atropine & 0.17 & $0.17^{*}$ & 0.18 & Yellowish brown \\
Promethazine & 0.5 & $0.5^{*}$ & 0.5 & Yellow \\
Albendazole & 0.85 & $0.83^{*}$ & 0.84 & Intense brown \\
Chlorpheniramine & 0.27 & $0.27^{*}$ & 0.27 & Bright yellows \\
Diclofenac sodium & 0.76 & 0.77 & 0.77 & \\
\hline
\end{tabular}

*The colour faint quickly.

The colour revealed depend on the doses of the drug (mentioned in the table (bold dose) each given to one rat of the 3 animals.

\section{Discussion}

When a clinician observes an animal with signs of poisoning, toxicological diseases which may be acute or chronic, and the clinical presentation will vary depending upon the route, extent, and frequency of exposure; the species involved; the time elapsed since the most recent exposure; and the route of exposure often influences the choice of specimens for confirmation (8).

Identifying an unknown substance in a biological fluid is a daunting task. It involves numerous steps: extraction, separation, and identification of the separated compound. Although the extraction of the acidic, neutral, and basic compounds is achieved by differential extraction, it is the separation and identification of the isolated compounds that pose the greatest challenge (3). In addition to these illicit compounds various drugs intended for medical use have been adopted into misuse (9).

The method described here is simple and rapid qualitative technique; a technician can carry out a check on a sample of blood or urine in $1 \mathrm{hr}$. The materials are readily available and inexpensive and need no specialized machine.

A simple analytical method for rapid screening of veterinary drugs is needed for use in areas that do not have fully equipped laboratories, it must be inexpensive, must require only limited facilities and minimum training, and must be capable of quickly analyzing the drugs, TLC method satisfies these requirements $(10,11)$, and have been recommended as an effective quality screening method for the investigation of veterinary drugs.

\section{Acknowledgment}

This wok was supported by College of Veterinary Medicine, University of Mosul.

\section{References}

1. Susan J, Bright DVM, Lynn Veterinary antidote and availability: an update (www.abvt.org/public/docs/antidoteupdate08.pdf) 2011.

2. Langman LJ, Kapur BM. Toxicology: then and now. Clin Biochem. 2006;39:498-510.

3. Loralie J, Langman, Bhushan M, Kapur Toxicology: then and now. J Clin Biochem. 2006;39:498-510.

4. Watson DG. Pharmaceutical Analysis :A Textbook for Pharmacy Students and Pharmaceutical Chemists. $2^{\text {ed }}$ ed. University of Strathclyde, Glasgow, UK. 2005;pp:316,318.

5. Clarke EGC. Isolation and Identification of Drugs in pharmaceuticals, body fluids and post mortem material, Pharmaceutical press, London.1978; (1):24,43-58.

6. Ahmad RA, Rogers RA. Plasma and salivary pharmacokinetics of dapsone estimated by a thin layer chromatographic method. Eur J Clin Pharmacol. 1980;17:129-133.

7. Taha IAK, Ahmad RA, Rogers HJ. Melphalan estimation by quantitative thin layer chromatography. Observation on melphalan hydrolysis in vitro and pharmacokinetics in rabbits. Cancer Chemotherapy Pharmacol. 1981;5:181-184.

8. Beasley V. Diagnosis and management of toxicoses. International Veterinary Information Service, Ithaca NY(www.ivis.org) 1999; A2602-0899.

9. Galloway $\mathrm{JH}$, Marsh ID. Detection of drug misuse-an addictive challenge. J Clin Pathol 1999;52:713-718.

10. Kenyon AS, Flinn PE, Layloff TP. Rapid screening of pharmaceuticals by thin layer chromatography: Analysis of essential drugs by visual methods. J AOAC international. 1995;78(1): 41-49.

11. Kale E, Risha P, Layloff Th. TLC for pharmaceutical analysis in resource limited countries. J Chromatogr A 2011; 1218: 2732-2736.

12. Adams RH. Veterinary pharmacology and therapeutics. $8^{\text {th }}$ ed. Iowa State University Press, Ames, USA. 2001; pp:132,280,330,409,656,951,1125 